\section{A tradução como método de ensino da Língua Portuguesa a estudantes japoneses}

Translation as a method for teaching Portuguese to Japanese students

\section{Abimael Maciel Marques (D) 0}

macielm84@gmail.com

Universidade de Estudos Estrangeiros de Tóquio (TUFS)

\section{Resumo}

A tradução como atividade de língua estrangeira (LE) ocupou, por muito tempo, uma posição de desprestígio em sala de aula. Em décadas mais recentes, contudo, houve o surgimento de novas ideias que defendem a reintrodução da atividade tradutória com um foco comunicativo. Dessa maneira, este trabalho, que se originou de uma pesquisa de doutorado da Universidade de Estudos Estrangeiros de Tóquio (TUFS), procura trazer à luz a questão da tradução como uma ferramenta para auxiliar os alunos japoneses de graduação no estudo da língua portuguesa. Tendo como base as ideias defendidas por House (1977), Harmer (2007) e Artar (2017) sobre o uso da tradução no ensino de LE, lançou-se a proposta de criar um minicurso com o intuito de trabalhar com atividades de tradução de quadrinhos com foco no desenvolvimento da competência comunicativa. Por meio de discussões sobre pontos específicos em sala, foi possível trazer aos alunos elementos culturais e linguísticos que se revelam importantes para uma comunicação eficaz com falantes brasileiros. As atividades forneceram dados que melhor sustentam a narrativa da tradução como um método que auxilia de maneira eficiente o aprendizado do português, fornecendo aos aprendizes japoneses um conhecimento maior a respeito de diferenças culturais e linguísticas, diminuindo, assim, possíveis mal-entendidos durante o processo comunicativo.

\section{Palavras-chave}

Tradução. Ensino. Língua Portuguesa. Competência Comunicativa.

\section{Abstract}

Translation as a foreign language (LE) activity has for a long time held a position of disrepute in the classroom. In more recent decades, however, new ideas have emerged that advocate the reintroduction of the translation activity with a communicative focus. In this way, this work, which originated from a doctoral research at the Tokyo University of Foreign Studies (TUFS), seeks to bring to light the issue of translation as a tool to assist Japanese undergraduate students in the study of the Portuguese language. Based on the ideas defended by House (1977), Harmer (2007) and Artar (2017) on the use of translation in foreign language teaching, a minicourse was created in order to carry out translation activities of comics focusing on the development of communicative competence. Through discussions on specific points during the class, it was possible to bring students cultural and linguistic elements that prove to be important for effective communication with Brazilian speakers. The activities provided data that better support the translation narrative as a method that efficiently helps Portuguese learning,

\section{Linguagẹm Foco}

Revista do Programa de Pós-Graduação em Linguística Aplicada da UECE

FLUXO DA SUBMISSÃO

Submissão do trabalho: 01/03/2021

Aprovação do trabalho: 28/07/2021

Publicação do trabalho: 13/10/2021

\section{COMO CITAR}

MARQUES, Abimael Maciel. A tradução como método de ensino da Língua Portuguesa a estudantes japoneses. Revista Linguagem em Foco, v.13, n.3, 2021. p. 114-125. Disponível em: https://revistas.uece.br/ index.php/linguagememfoco/article/view/5026. 
providing Japanese students with greater knowledge about cultural and linguistic differences; thus, reducing possible misunderstandings during the communicative process.

Keywords

Translation. Teaching. Portuguese language. Communicative competence.

\section{Introdução}

O uso da tradução no ensino de língua estrangeira (LE) é um tema por deveras polêmico, uma vez que é visto, por muitos acadêmicos e professores da área, como um método que pode trazer malefícios ao estudante e, por conseguinte, não deve ser incorporado no contexto de sala de aula. Muitos apontam para o fato de que a sua utilização acarreta uma interferência negativa por parte da língua materna do aprendiz e, como pontua Heltai (1989, p. 292), pode se tornar uma atividade contraproducente no contexto de aprendizagem. No entanto, indo de encontro à marginalização da tradução, como acontece, por exemplo, no Método Natural e na Abordagem Comunicativa, nas últimas décadas houve o fortalecimento de uma corrente de estudos que se propôs a resgatar a relevância das atividades tradutórias nas aulas de LE. Pinar Artar (2017) discute esse tema afirmando que "você não pode simplesmente agir como se não tivesse nenhum conhecimento linguístico da $\mathrm{L} 1$ enquanto está aprendendo uma nova língua"1 (ARTAR, 2017, p. 38). Dessa maneira, ao invés de se negar o uso de um método que é utilizado de forma natural por alunos durante o aprendizado, seria de grande interesse a busca por um modo de fazer uso da tradução com o intuito de incluí-la em sala de aula como um amparo ao aprendizado da LE.

Levando em consideração o exposto acima, o presente trabalho se insere na interseção entre a tradução e o aprendizado de LE e propõe adentrar nessa área ainda bastante polêmica com o intuito de analisar se a atividade tradutória pode, de fato, fornecer pontos positivos no tocante ao aprendizado de uma língua estrangeira, mais especificamente ao do português brasileiro no contexto universitário japonês.

\section{Tradução e Ensino}

A tradução como método didático no contexto de LE tem sido um tópico de grande debate na área de ensino e aprendizagem de idiomas, e muitos estudiosos a criticam por diversos fatores, sendo um deles ela não possuir um valor

1 Original: you cannot simply act as if you do not have any L7 linguistic knowledge while you are learning a new language. 
comunicativo para os aprendizes, como aponta Carreres (2006). A autora debruça-se sobre a temática ao comentar que há a crença de que a "tradução é um exercício artificial e engessado que não tem lugar em uma metodologia comunicativa. Ela é restritiva ao confinar a prática somente a duas habilidades (leitura e escrita)² (CARRERES, 2006, p. 5). Contudo, é necessário observar que o modo de conceber a tradução como uma atividade pedagógica deve levar em conta vários fatores que por vezes são negligenciados. House (1977, p. 228) afirma que a comunicação se estabelece através de equivalências pragmáticas relacionadas às formas linguísticas como enunciados. Em outras palavras, há a necessidade de se buscar outro olhar para a tradução, a fim de trabalhá-la por meio de atividades comunicativas capazes de engajar o aluno durante o processo de aprendizado.

Com relação à interferência da língua nativa, há a crença de que a tradução pode levar o aprendiz a pensar que sempre haverá uma equivalência direta entre palavras de idiomas diferentes. Carreres (2006, p. 5) argumenta que "a tradução para uma segunda língua (L2) é contraproducente, pois força o aluno a ver a língua estrangeira sempre através do prisma de sua língua nativa; isso causa interferências e uma dependência da L1 que inibe o livre uso da L2."3 Todavia, essa ideia pode ser discutida a partir do ponto de vista de estudiosos como Harmer (2007), que encaram a atividade tradutória como um processo mental que ocorre geralmente de forma natural. De acordo com o autor, já que os aprendizes tendem a fazer comparações entre a língua materna e o idioma estrangeiro, pode-se usar essa oportunidade para mostrar aos estudantes os tipos de erros comuns, tendo como base uma análise contrastiva entre as duas línguas (HARMER, 2007, p. 133).

A partir do momento em que se leva em consideração o fato de que o ser humano faz uso de conhecimentos já existentes para adquirir novos, as atividades tradutórias acabam, assim, por conduzir o aprendiz a contemplar não somente a língua estrangeira, mas também a sua própria, a partir de uma nova perspectiva de aprendizagem. O intuito do uso da tradução, portanto, é o de ensinar ao aluno, por meio de um ponto de vista comunicativo, aspectos linguísticos e culturais da língua estrangeira. Através de discussões em sala de aula a respeito das diferenças e semelhanças entre os idiomas, aos alunos é dada a oportunidade de comparar a sua própria língua e a língua do ou-

2 Original: Translation is an artificial, stilted exercise that has no place in a communicative methodology. Also, it is restrictive in that it confines language practice to two skills only (reading and writing).

3 Original: Translation into $L 2$ is counterproductive in that it forces learners to view the foreign language always through the prism of their mother tongue; this causes interferences and a dependence on L1 that inhibits free 
tro, levando-os, dessa maneira, a serem capazes de adquirir conhecimentos através de um método que se propõe a mostrar o uso adequado de palavras e expressões, bem como valores culturais, a partir de contextos situacionais.

\section{Contextualizando a pesquisa}

A pesquisa foi realizada através de um minicurso de tradução com estudantes de três universidades da região de Kanto, Japão: Universidade de Estudos Estrangeiros de Tóquio (TUFS), Universidade Sophia e Universidade Kanda de Estudos Internacionais (KUIS). A partir do momento em que não foi possível utilizar as aulas curriculares para a condução da pesquisa, houve uma chamada para os alunos interessados participarem do minicurso. A pesquisa se desenvolveu em dois períodos, sendo que o primeiro, que ocorreu no semestre de outono de 2018 , teve características de estudo piloto, uma vez que foi necessário entender a dinâmica de cada instituição e o modo como os alunos japoneses lidavam com as atividades propostas de acordo com o seu nível linguístico e dentro de um novo modelo de aula. Dessa forma, na primeira etapa, houve adesão de dois alunos da TUFS, um aluno da Universidade Sophia e quatro alunos da KUIS. Já na segunda etapa, houve a adesão de três alunos da TUFS, quatro da Universidade Sophia e quatro da KUIS. Em relação ao nível de português, todos tinham pelo menos um ano de estudos do idioma, sendo que seis já haviam realizado intercâmbio no Brasil. O minicurso foi constituído de seis aulas, que aconteceram nas dependências das três universidades, e tiveram duração de 90 minutos cada, totalizando nove horas.

\section{Metodologia}

Este trabalho teve como ponto de partida o desejo de dar prosseguimento a uma pesquisa iniciada em nível de mestrado, na qual atividades de tradução foram realizadas com um grupo de alunos brasileiros de língua japonesa com o intuito de desenvolver a sua habilidade tradutória. Por conseguinte, a atual pesquisa de doutorado, que está em andamento em uma instituição de ensino superior japonesa, utiliza-se da pesquisa-ação, que, por definição, baseia-se no pressuposto de que o pesquisador participe como membro ativo de sua própria pesquisa e, em conjunto com todos aqueles envolvidos no processo estabeleça diretrizes que vão moldando a maneira como se busca soluções para um determinado problema, como descreve Franco (2005) em seu trabalho a respeito do 
tema: "A pesquisa deve partir de uma situação social concreta a modificar e, mais que isso, deve se inspirar constantemente nas transformações e nos elementos novos que surgem durante o processo e influência da pesquisa" (FRANCO, 2005, p. 486).

A pesquisa-ação, assim, surge como um modo de o professor ter a oportunidade de identificar as dificuldades dos alunos e, consequentemente, poder introduzir revisões em sua pesquisa para que ela se adeque à realidade que está em constante construção. Por meio de uma reflexão sobre sua própria prática dentro de sala de aula, há uma abertura para que as opiniões dos participantes sejam discutidas e uma flexibilidade para que o aprendizado se realize através de discussões, trazendo aos alunos uma consciência mais crítica e concreta sobre o desenvolvimento de seu próprio aprendizado.

\section{Instrumentos de coleta}

Com a finalidade de assegurar maior confiabilidade ao material coletado, bem como evitar uma análise tendenciosa das informações, optou-se por utilizar a triangulação de dados, uma vez que ela se apresenta como um método que permite uma apreciação dos fatos através de perspectivas diversas obtidas por diferentes instrumentos. Através das informações analisadas por meio da comparação de diferentes meios, o pesquisador tem uma visão mais ampla e confiável do modo em que a realidade se apresenta. Dito isso, os três instrumentos utilizados foram: pré-teste e pós-teste, questionários e atividades em sala de aula com relatórios.

Em relação ao primeiro instrumento, ele visa mensurar a maneira como os alunos desenvolvem suas habilidades e percepções sobre uma determinada proposta praticada em sala de aula. Esse instrumento possibilita ao pesquisador medir a evolução dos aprendizes em dois pontos opostos do processo, uma vez que o mesmo teste é aplicado tanto no início como no final do tempo de aprendizado. No caso específico desta pesquisa, a comparação entre as duas traduções surge como uma ferramenta de grande valor, pois traz à luz a mudança de atitude do estudante em relação ao ato tradutório após as atividades em sala, discussões e, por conseguinte, aquisição de novos conhecimentos.

Os questionários, por sua vez, têm por objetivo sondar o conhecimento prévio dos sujeitos da pesquisa a respeito do assunto a ser trabalhado nas aulas, bem como suas crenças oriundas de experiências pessoais, que podem impactar o modo como eles lidam com a temática a ser abordada nas aulas. Uma vez que 
há a aplicação tanto no primeiro momento das aulas quanto no último dia, pode-se observar com uma maior clareza a maneira através da qual os aprendizes assimilam o conteúdo a respeito da tradução e se tornam mais conscientes sobre a sua utilidade para o aprendizado da língua estrangeira.

Por fim, há as atividades em sala de aula e seus respectivos relatórios. Com exceção da primeira e da última aula do minicurso, os outros quatro encontros tiveram foco em atividades de tradução do gênero quadrinhos. As histórias escolhidas foram as da Turma da Mônica, visto que são de caráter deveras popular para o público brasileiro e, portanto, trazem contextos situacionais que refletem o cotidiano social e o modo de interação entre os indivíduos através de uma linguagem natural. Esses aspectos sociais são de grande interesse para o aprendiz japonês, uma vez que fazem com que ele se aproxime mais da cultura brasileira e desenvolva estratégias comunicacionais que, por vezes, não são contempladas em aulas tradicionais em cursos regulares dentro ou fora do ambiente universitário.

Durante as aulas, os alunos realizaram as traduções de forma individual e, em seguida, através de discussões em grupo, relataram os pontos mais desafiadores percebidos durante o processo tradutório. Nesse momento, em conjunto como professor-pesquisador, eles foram encorajados a expor suas opiniões e a fazer comparações no que tange ao modo como o brasileiroe ojaponês interpretam a mesma realidade a partir de pontos de vistas moldados por diferentes aspectos culturais. Ademais, foi requisitado aos alunos que respondessem um relatório com perguntas definidas que se relacionavam ao que foi traduzido e discutido em sala de aula.

Por meio dessa ferramenta, portanto, pretende-se fornecer uma maneira para que estudantes japoneses possam refletir, através de sua própria experiência, sobre questões culturais e sociais que estão incorporadas no modo de falar e interagir dos brasileiros, fazendo com que a comunicação entre indivíduos de ambas culturas ocorra de uma maneira fluida e sem ruídos na comunicação. $\mathrm{Na}$ seção seguinte, haverá um recorte da análise de dados com foco na ferramenta de atividades de tradução e seus relatórios correspondentes.

\section{Análise das atividades de tradução}

Durante o minicurso, as atividades de tradução ocorreram em quatro aulas de 90 minutos cada. Aos alunos foi dada, a cada encontro, uma história específica da Turma da Mônica e pedido que a traduzissem do português para o japonês. Após as atividades, houve discussão a respeito dos pontos mais relevantes 
e difíceis para os alunos. Abaixo, há um excerto da história traduzida na segunda aula:

Figura 1 - Turma da Mônica4

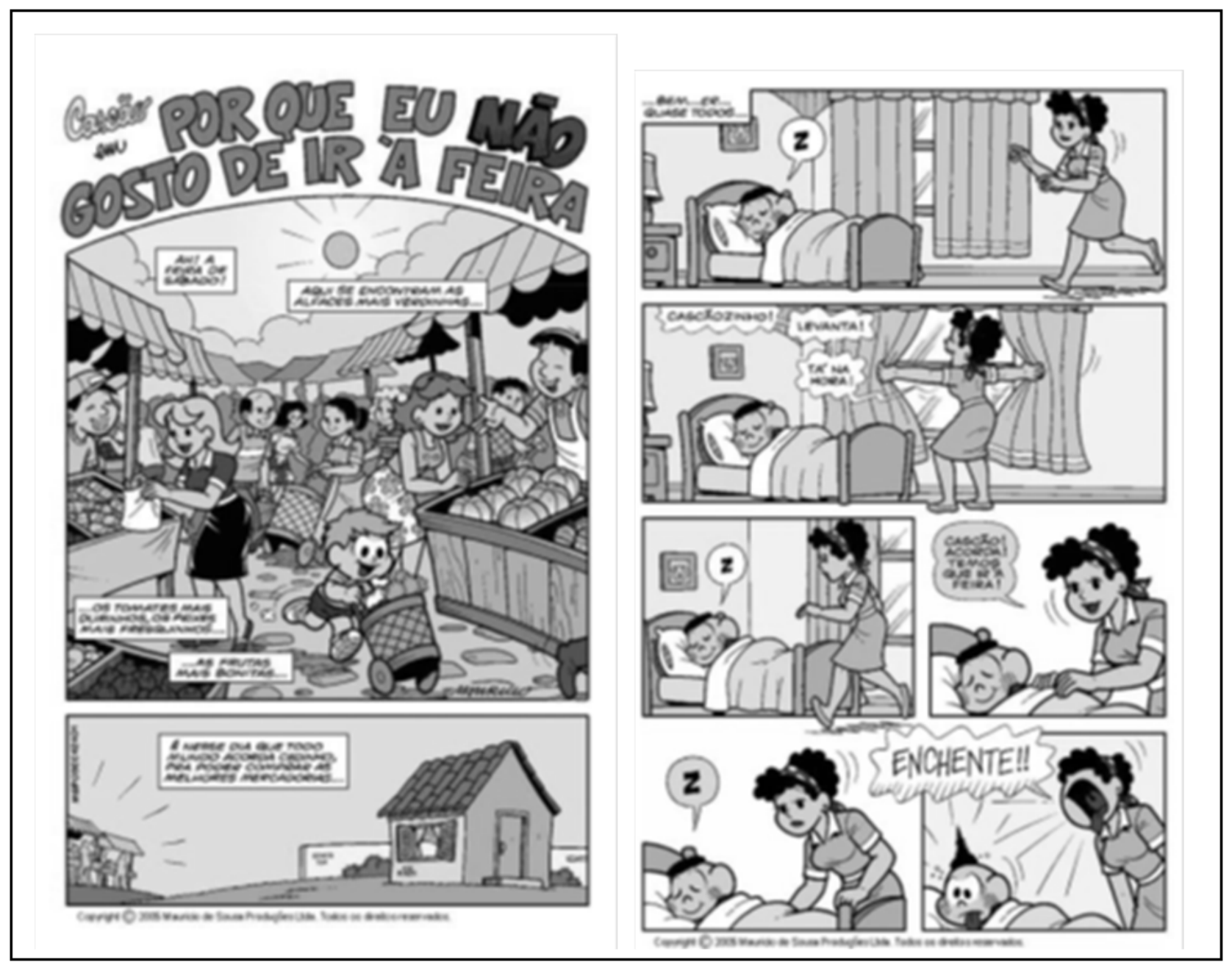

Fonte: SOUSA, Mauricio Araújo de. Cascão n 424. Globo, 2003. 68 p.

Tomando como ponto de partida para a análise o título da história acima, percebe-se que se trata de um evento que é bastante comum em diversas cidades brasileiras. As feiras de rua, também conhecidas como feiras livres, acontecem, muitas vezes, em determinado dia e horário da semana. Nesses locais, encontram-se diversos tipos de produtos, como, por exemplo, frutas e verduras. O título da história remete a uma feira que ocorre aos sábados e, nesse dia, o personagem Cascão vai até lá fazer compras com sua mãe.

O sujeito 5, a respeito desse fato, comenta o seguinte sobre a tradução da

4 As histórias traduzidas no minicurso foram retiradas do site http://turmadamonica.uol.com.br/ quadrinhos. Acesso em: 01 set. 2018. 
palavra feira:

Pensei que 青空市場 (aozoraichiba) ficaria melhor, mas não existe a ideia em japonês. Às vezes vejo uma feira com o nome マルシェ (marushe) nestes dias, (algo) que seja mais próximo à ideia de feira no Brasil.

O aluno acima, em sua tradução, decidiu pelo termo 青空市場 (aozoraichiba), muito provavelmente por ser algo que seja mais perceptível em sua vida no Japão. De acordo com os alunos, aozoraichiba seria um tipo de feira que ocorre em praças e em frente a templos, onde geralmente verduras e outros tipos de gêneros alimentícios são vendidos. O aluno também comenta sobre ○ マルシェ (marushe), oriundo da palavra francesa marché5, que, pela discussão em grupo, é um lugar que se assemelha bastante ao modo como as feiras acontecem nas cidades brasileiras, contudo possui um ar de elegância, ocorrendo até mesmo em ambientes fechados de bairros nobres. De todo modo, ficou claro que os alunos não tinham muita noção de como as feiras funcionam no Brasil, em especial pelo fato de elas oferecerem preços mais vantajosos do que outros locais tradicionais, como supermercados e shopping centers. Outra característica desconhecida pelos alunos foi a questão de que há diferentes tipos de feiras, nas quais há a possibilidade de se comprar roupas, calçados, eletrônicos, artesanato, comidas típicas e muitos outros produtos em um ambiente em que há competição entre os vendedores e uma grande barganha feita pelos consumidores em relação ao preço das mercadorias. Ao comparar a feira brasileira e o aozoraichiba e maruche japonês, foram traçadas similaridades e diferenças entre esses termos e foi possível ampliar o entendimento desse tipo de local no contexto social brasileiro.

Na história também há vários exemplos de palavras usadas na forma do diminutivo, que é uma parte da gramática do português que os alunos japoneses estudam tendo como explicação principal a questão de os substantivos e adjetivos expressarem uma característica diminuída em relação ao grau normal. Entretanto, no português brasileiro, a forma diminutiva vai além e pode ser utilizada também, dependendo do contexto, para passar a noção de "menosprezo", bem como transmitir a ideia de "afeição" e "aproximação" do falante com o seu interlocutor. No texto, encontramos palavras como "verdinhas", "durinhos", "fresquinhos" e "cedinho" e, sobre o modo como o diminutivo poderia ser traduzido para japonês, os sujeitos 1 e 4 relataram o seguinte:

5 "Mercado" em francês. Consulta no dicionário online www.infopedia.pt/dicionarios/frances-portugues/ marché. 
No caso de nomes de pessoas com diminutivo, é melhor colocar <h (kun) e ちゃん (chan) ${ }^{6}$ no final do nome. No caso de adjetivo com diminutivo que dá aproximação, é melhor usar palavra que não é exatamente de tradução, mas tem sentido mais aproximado (sujeito 1).

Para dar um tipo de sensação diferente, poderia usar mais onomatopeias (sujeito $4)$.

O interessante é ver o modo como os dois sujeitos acima ponderam sobre a questão do uso do diminutivo. O sujeito 1, em sua tradução, decidiu traduzir alfaces mais verdinhos e peixes mais fresquinhos utilizando o mesmo adjetivo 新鮮 (shinsen), que dá a ideia de algo novo ou fresco. Para ele, a maneira de transmitir a ideia de proximidade do diminutivo vem com a escolha de palavras que muitas vezes não são equivalentes ao original em português. Já esse mesmo sujeito, na expressão "tomates mais durinhos", acabou por deixar o espaço em branco e só traduziu tomates. Pela discussão em sala, a ideia de usar a palavra duro nesse contexto para afirmar que o tomate está bom é algo estranho em japonês. A palavra 固い(katai), que significa duro em japonês, soaria muito estranha e não seria natural, algo que já é diferente em português. Por isso, o sujeito 4, como disse em seu relato, traduziu essa mesma expressão como つやつやのトマト (tsuyatsuya no tomato), que, em português, seria "tomate lustroso" ou tomate brilhante, colocando a expressão mais natural em japonês e traçando um paralelo no sentido de se afirmar que nem sempre o uso de duro em português e japonês terá o mesmo significado semântico.

Por fim, no último quadrinho da segunda página, quando a mãe do personagem Cascão tenta acordá-lo para ir à feira e não obtém sucesso, ela decide gritar "enchente" como uma forma de assustá-lo e fazê-lo levantar da cama. Além do fato de o Cascão não gostar de água, o uso da palavra "enchente" também pode se relacionar à realidade de muitos lugares no Brasil onde ocorrem alagamentos. Não é raro encontrar cidades que não estão preparadas para chuvas torrenciais e acabam sofrendo inundações, algo que, dependendo da área onde o indivíduo mora, pode trazer grande perigo para a sua integridade física. Por outro lado, os alunos informaram que "enchente" não causaria um grande impacto em criar uma reação de susto no personagem. O sujeito 4 explica:

Fogo, incêndio「火事だ!」7é usado em mangás, literaturas e outras obras ficcionais

6 Kun e chan são termos honoríficos colocados após nomes e sobrenomes de pessoas para indicar o grau de relação social entre os indivíduos.

7 火事だ(kaji) significa fogo em japonês. 
desde antigamente. Caso de emergência mais possível no Japão é terremoto, mas o terremoto acorda a pessoa, então usa-se "fogo", que vem em segundo (sujeito 4)

Aqui já se nota o modo como o sujeito discute o impacto que há entre o uso de enchente no Brasil e como ela seria encarada no Japão. Para um japonês, o impacto dessa palavra, de acordo com os alunos, já não seria tão grande quanto o uso de "incêndio" ou "terremoto". Esse fato é corroborado pelo sujeito 1 quando ele relata:

Eu acho que (enchente) não causaria (impacto) porque enchente não acontece frequentemente no Japão. Por isso, os japoneses não ficam assustados. No Japão, incêndio tem o mesmo efeito que enchente no Brasil (sujeito 1)

Novamente, nota-se que a discussão em sala de aula foi de grande valia e levou os alunos a entrarem em um consenso de que diferentes lugares possuem modos distintos de encarar e temer desastres, sendo eles naturais ou não. No caso em questão, os alunos tiveram a oportunidade de comparar o modo como desastres, tais como inundações, incêndios e terremotos, por exemplo, são percebidos e encarados pelos indivíduos tanto no Brasil quanto no Japão. Esse tipo de situação também suscitou discussão a respeito de como ambos os países lidam com a prevenção de calamidades públicas, algo que afeta diretamente a relação de bem-estar e segurança dos cidadãos em seu âmbito social.

Em resumo, a atividade de tradução foi uma porta aberta para discussões que vão além de aspectos linguísticos dos idiomas português e japonês e adentram nas esferas culturais e sociais. Há a possibilidade de fazer paralelos a respeito de como a sociedade é organizada nos dois países e de como isso afeta a maneira como brasileiros e japoneses se comportam em diferentes contextos de comunicação.

\section{Considerações Finais}

A tradução, atividade que, por muitas décadas, foi alocada em uma posição marginalizada no ensino-aprendizagem de línguas estrangeiras, voltou recentemente a ser estudada por teóricos e educadores com o objetivo de reformular o seu uso dentro do contexto de sala de aula. Embora ainda haja, até certo ponto, a crença de que o professor deve evitar usar a língua materna do aprendiz, pois isso pode desfavorecer a aquisição do idioma estrangeiro, pesquisas como esta apresentam uma nova abordagem para se trabalhar com atividades tradu- 
tórias, tendo por finalidade auxiliar o aluno no aprendizado da língua-alvo. Dessa maneira, a tradução ressurge não com o objetivo de se tornar o foco das aulas, mas como um método que pode trazer muitos benefícios, se utilizado em uma concepção comunicativa.

No contexto do presente trabalho, buscou-se trazer atividades tradutórias para serem realizadas em sala de aula com o intuito de se discutir as diferenças entre o português brasileiro e a língua japonesa, e como língua e cultura são dois elementos que andam lado a lado, houve sempre espaço para o debate de aspectos culturais e sociais, uma vez que eles possuem grande relevância no momento da comunicação, sendo, portanto, essenciais para o aprendizado da língua portuguesa.

Por meio da análise dos dados, foi possível verificar a eficácia da tradução como uma ferramenta que oferece aos alunos uma perspectiva diferente para o aprendizado da língua portuguesa. Durante o minicurso de tradução, observou-se a evolução dos alunos em suas próprias escolhas tradutórias a partir do momento em que eles levaram em consideração a questão das diferenças existentes nos contextos de fala do português e do japonês. O desenvolvimento da competência comunicativa através das atividades tradutórias acontece de uma forma dinâmica e vai de encontro a uma tradição de uso passivo da tradução. Nessa nova abordagem comunicativa, os alunos japoneses são levados a questionar a sua própria realidade linguística e cultural ao mesmo tempo que ponderam e dão maior importância para o seu interlocutor brasileiro, que é oriundo de um contexto cultural tão diferente.

As histórias da Turma da Mônica, por sua vez, se mostraram de grande valia para os alunos, pois eles tiveram a chance de trabalhar com traduções por meio de um gênero textual lúdico que facilita a compreensão através de imagens. Pelas discussões e relatos dos sujeitos da pesquisa, ficou evidente que os quadrinhos facilitam o entendimento dos diálogos e, por conseguinte, a tradução para o japonês. Ademais, a linguagem das histórias, apesar de ter um foco no público infantil, é rica em palavras e expressões cujo entendimento requer uma compreensão adequada da cultura brasileira, levando os aprendizes a lidarem constantemente com situações que os fazem refletir sobre o modo como a comunicação deve ser feita, a fim de evitar mal-entendidos.

Dessa maneira, esta pesquisa chega à sua conclusão estabelecendo um meio de aprimorar o ensino do português brasileiro para falantes de japonês por meio de uma metodologia que busca trazer uma nova perspectiva para a tradução dentro do contexto de sala de aula. Através de um ambiente de ensino- 
-aprendizagem no qual tanto o professor quanto os alunos se tornam o centro do processo, há uma constante reflexão sobre a condução das aulas e sobre como o conhecimento é construído pelos participantes. Através dessa construção, a tradução se torna uma ferramenta de grande valia que auxilia na superação de barreiras linguísticas e culturais que surgem durante o ato comunicativo entre falantes brasileiros e japoneses.

\section{Referências}

ARTAR, P. The role of translation in foreign language teaching. 2017. $260 \mathrm{f}$. (Doutorado em Estudos Culturais) - Universitat Rovira I Virgili, Tarragona, Itália, 2017. Disponível em: https://www. tdx.cat/bitstream/handle/10803/461885/TESI.pdf. Acesso em: 30 jan. 2020.

CARRERES, A. 2006. Strange bedfellows: Translation and language teaching. In The teaching of translation into L2 in modern Languages degrees, uses and limitations. Sixth Symposium on Translation, Terminology and Interpretation in Cuba and Canada: December 2006. Canadian Translators, Terminologists and Interpreters Council. Disponível em: http://www.cttic.org/ ACTI/2006/papers/Carreres.pdf. Acesso em: 03 mar. 2020.

FRANCO, M. A. Pedagogia da Pesquisa-Ação. Revista Educação e Pesquisa. v. 31, n. 3, p. 483502, São Paulo, set./dez. 2005.

HELTAI, P. Teaching vocabulary by oral translation. ELT Journal. Oxford: OUP p. 289-293, 1989.

HARMER, J. The Practice of English Language Teaching (4th ed.). Pearson Education, 2007.

HOUSE, J. Acquiring translational competence in interaction. In: J. House \& S. Blum-Kulka, 1986.

HOUSE, J. A Model for Translation Quality Assessment. Tubingen: TBL Verlag Gunter Narr, 1997.

\section{Sobre o autor}

Abimael Maciel Marques - Doutorando do Programa de Pós-Graduação em Estudos Globais da Universidade de Estudos Estrangeiros de Tóquio (TUFS); Tóquio - Japão E-mail: macielm84@gmail.com. Lattes: http://lattes.cnpq.br/8499512141409155. OrclD: https:// orcid.org/0000-0001-7641-1840 